\title{
Designing Business Models for the Internet of Things
}

\section{Mika Westerlund, Seppo Leminen, and Mervi Rajahonka}

\author{
"New web-based business models being hatched for the" \\ Internet of Things are bringing together market players who \\ previously had no business dealings with each other. \\ Through partnerships and acquisitions, [...] they have to sort \\ out how they will coordinate their business development \\ efforts with customers and interfaces with other stakeholders.
}

\author{
Stefan Ferber \\ Director for Business Development of the Internet of Things \& \\ Services at Bosch Software Innovations $\mathrm{GmbH}$ \\ HBR Blog Network, May 7, 2013
}

\begin{abstract}
This article investigates challenges pertaining to business model design in the emerging context of the Internet of Things (IOT). The evolution of business perspectives to the IOT is driven by two underlying trends: i) the change of focus from viewing the IOT primarily as a technology platform to viewing it as a business ecosystem; and ii) the shift from focusing on the business model of a firm to designing ecosystem business models. An ecosystem business model is a business model composed of value pillars anchored in ecosystems and focuses on both the firm's method of creating and capturing value as well as any part of the ecosystem's method of creating and capturing value. The article highlights three major challenges of designing ecosystem business models for the IOT, including the diversity of objects, the immaturity of innovation, and the unstructured ecosystems. Diversity refers to the difficulty of designing business models for the IOT due to a multitude of different types of connected objects combined with only modest standardization of interfaces. Immaturity suggests that quintessential IOT technologies and innovations are not yet products and services but a "mess that runs deep". The unstructured ecosystems mean that it is too early to tell who the participants will be and which roles they will have in the evolving ecosystems. The study argues that managers can overcome these challenges by using a business model design tool that takes into account the ecosystemic nature of the IOT. The study concludes by proposing the grounds for a new design tool for ecosystem business models and suggesting that "value design" might be a more appropriate term when talking about business models in ecosystems.
\end{abstract}

\section{Introduction}

According to Gershenfeld and Vasseur (2014) the impressive growth of the Internet in the past two decades is about to be overshadowed as the "things" that surround us start going online. The "Internet of Things" (IOT), a term coined by Kevin Ashton of Procter \& Gamble in 1998, has become a new paradigm that views all objects around us connected to the network, providing anyone with "anytime, anywhere" access to information (ITU, 2005; Gomez et al., 2013). The IOT describes the interconnection of objects or "things" for various purposes including identification, communication, sensing, and data collection (Oriwoh et al., 2013). "Things" range from mobile devices to general household objects embedded with capabilities for sensing or communication through the use of technologies such as radio frequency identification (RFID) (Oriwoh et al., 2013; Gomez et al., 2013). The IOT represents the future of computing and communications, and its develop- 


\title{
Designing Business Models for the Internet of Things
}

\author{
Mika Westerlund, Seppo Leminen, and Mervi Rajahonka
}

ment depends on dynamic technical innovation in fields such as RFID, sensor technologies, smart things, nanotechnology, and miniaturization (ITU, 2005).

The strategic research agenda of the Cluster of European Projects on the Internet of Things (CERPIoT, 2009) suggests that the IOT is expected to change business, information, and social processes, and provide many unforeseen possibilities. According to Kyriazis and Varvarigou (2013), the dynamic, rapidly changing, and technology-rich digital environment of the IOT enables the provision of added-value applications that exploit a multitude of devices contributing to services and information. Moreover, they add that, as technologies for the IOT mature and become ubiquitous, emphasis will be put upon approaches that allow things to become smarter, more reliable, and more autonomous. However, research on the IOT and related business models from the ecosystem perspective have been virtually nonexistent, because the scarce studies on the IOT have focused on the technological platform and a single firm's business models (Uckelmann et al. 2011; Leminen et al., 2012). Therefore, this study examines business model design under the transition from company-specific business models towards networked and more comprehensive ecosystem business models. In particular, the study focuses on the challenges that hinder the emergence of IOT business models.

This conceptual study is organized as follows. First, after this brief introduction, we review the theoretical background of paradigm changes regarding ecosystems and business models related to the IOT. Second, we discuss the major challenges of designing business models for the IOT. Third, we approach these challenges by proposing grounds for a new tool for designing ecosystem business models for the IOT. Finally, we conclude by reviewing our key implications.

\section{Theoretical Background}

In today's networked world, businesses are becoming parts of complex business ecosystems. This complexity increases when transforming from centralized towards decentralized and distributed network structures (Barabasi, 2002; Möller et al., 2005). Different structures emphasize different types of activities in the ecosystem, and a continuously increasing level of complexity calls for new types of value systems (cf. Möller et al., 2005). Muegge (2011) describes business ecosystems as institutions of participation "where organizations and individuals typically self-identify as an ecosystem, both in their own internal discourse and in the brand identity they convey to others". He also points out that a business ecosystem refers to an organization of economic actors whose individual business activities are anchored around a platform, and that a platform is an organization of things.

The technological platform forms the core of a business ecosystem (Cusumano \& Gawer, 2002). Muegge (2011) defines a platform as a set of technological building blocks and complementary assets that companies and individuals can use and consume to develop complementary products, technologies, and services. Furthermore, Muegge (2013) presents a system of systems view (i.e., an "architecture"), according to which a platform is an organization of things (e.g., technologies and complementary assets), a community is an organization of people, and a business ecosystem is an organization of economic actors. Therefore, the core of an IOT ecosystem refers to the interconnections of the physical world of things with the virtual world of Internet, the software and hardware platforms, as well as the standards commonly used for enabling such interconnection (Mazhelis et al., 2012).

Moore (1996) defines a business ecosystem as "an economic community supported by a foundation of interacting organizations and individuals." A business ecosystem includes customers, lead producers, competitors, and other stakeholders. He argues that the leadership (keystone) companies have a strong influence over the co-evolutionary processes. Peltoniemi (2005) refers to systems theory by arguing that "the system is more than the sum of its parts" and reminds us that the operation of the system cannot be understood by studying its parts detached from the entity. She also argues that a socio-economic system such as a business ecosystem is a complex adaptive system, and that its population develops through co-evolution with the greater environment, self-organization and emergence (i.e., the ability and process to create new order), and adaptation to the environment.

\section{From the business model of a firm to ecosystem business models}

Since the early 2000s, the concept of "business model" has surged into management vocabulary, and the use of the term has become fashionable (Shafer et al., 2005). It is a powerful concept (Zott \& Amit, 2008) and has become of increasing importance since the dot.com era (Demil \& Lecocq, 2010). The academic research into business models is under developed, with no commonly accepted view of what the business mod- 


\title{
Designing Business Models for the Internet of Things
}

\author{
Mika Westerlund, Seppo Leminen, and Mervi Rajahonka
}

el should consist of (Morris et al., 2005; Osterwalder et al., 2005; Schweizer, 2005). According to Zott, Amit, and Massa (2011), previous literature has viewed a business model in a multitude of ways, including a statement, a description, a representation, an architecture, a conceptual tool or model, a structural template, a method, a pattern, and a set. Furthermore, they found that the business model is often studied without an explicit definition of the concept.

In general, the thinking around business models has changed over the past decade. According to Achtenhagen, Melin, and Naldi (2013), there has been a fundamental change from "what business models are" towards understanding "what business models are for". There seems to be a consensus among scholars that a business model spells out a particular firm's way of doing business (cf. Osterwalder et al., 2005; Rajala \& Westerlund, 2008; Casadesus-Masanell \& Ricart, 2010; Teece, 2010). For example, Osterwalder, Pigneur, and Tucci (2005) argue that "a business model is the blueprint of how a company does business". Moreover, business models are understood as entities, breakable into components or various modules. Shafer, Smith, and Linder, (2005) identify up to 20 different business model components categorized into four main areas, and Osterwalder and Pigneur (2010) discuss the various components as nine pillars. Muegge (2012) uses the components view to provide a method of business model discovery for technology entrepreneurs.

Although scholars are unified in their view of the business model as a firm-level construct, they emphasize its systemic nature (Rajala \& Westerlund, 2008). For instance, Timmers (1998) describes business model as the "architecture of the product, service and information flows, including a description of the various business actors and their roles; a description of the potential benefits for the various business actors; and a description of the sources of revenues". The literature on business ecosystems suggests the need for a deeper network view on business models (cf. Carbone, 2009; Muegge, 2013). Existing business model templates and frameworks are adequate when examining the challenges faced by single existing organizations but are less suited to analyzing the interdependent nature of the growth and success of companies that are evolving in the same innovation ecosystem (Weiller \& Neely, 2013). Considering the development of the IOT field, it is clear that interdependency due to being connected with other actors through technical and business ties is becoming more and more essential.

\section{Pitfalls of Making Money in the Internet of Things}

Previous research is nearly silent of the challenges related to monetizing the IOT. Wurster (2014) is among the few to categorize the barriers that prevent companies from moving ahead in terms of making money with the IOT. According to her, the IOT has a major technological impact, which brings about problems for companies. These issues include the challenge of identifying horizontal needs and opportunities, the managerial challenge related to internal team alignment (i.e., matching technology and to the objectives of business developers), and the ways to overcome the market maturity problem for novel IOT technology. We extend this view and identify three contemporary challenges of the IOT, comprising the diversity of objects, the immaturity of innovation, and the unstructured ecosystems. These challenges are generated based on a literature review and discussions with experts on the IOT. Relying on Muegge (2011), these challenges focus on platform, developer community, and business ecosystem spheres of the formation of IOT-based ecosystem business models.

\section{Diversity of objects}

The problem of diversity of objects refers to the difficulty in designing business models for the IOT due to a multitude of different types of connected objects and devices without commonly accepted or emerging standards. The IOT is a network of interconnected objects (Evans, 2011), where everything from toothbrushes and sportswear to refrigerators and cars will have an online presence. For all these different kinds of "things", it will be extremely challenging to standardize the interfaces with which they can connect to the Internet. The diversity of objects brings about another challenge for managers given that there are virtually endless ways of connecting an object, a thing, a business, and a consumer together (Leminen et al., 2012). Therefore, a continuum of possible business models is increasing. Whereas recent estimates put forward that there are presently 10 billion connected devices and there will be 50 billion devices by 2020 , more than 99 percent of physical objects that may one day join the network are still not connected (Evans, 2011). These estimates suggest that an unprecedented number of objects will be part of the future Internet. In addition, Espada and colleagues (2011) note that more and more physical objects, called "things", are becoming available in digital format. These "virtual objects" are digital elements that have a specific purpose, comprise a series of data, and can perform actions. They integrate with other applications and physic- 


\section{Designing Business Models for the Internet of Things}

\section{Mika Westerlund, Seppo Leminen, and Mervi Rajahonka}

al "things", and may require specific business logics (Espada et al., 2011).

\section{Immaturity of innovation}

Immaturity refers to the current "mess" of emerging technologies and components: today's quitessential IOT innovations have not yet matured into products and services. They have not yet been standardized or modularized for wider usage and often require engineering work to couple them together in another application area. Modularized objects, including a "plug and play" character of components, are prerequisites for the emerging market. Coupling components together enables developers to experiment and create products and services for an IOT ecosystem, as well as to learn from market experiences when designing business models. The popular model of the technology adoption lifecycle (cf. Moore, 2006) recognizes five types of adopters of innovation, including innovators, early adopters, early majority, late majority, and laggards. The major challenge is to advance from early adopters to early majority, because the business model must allow for "scaling up" the business. The early adopters are willing to tolerate the immaturity of innovation, but the early majority likes to evaluate and buy whole products, including the product, ancillary products, and any related services (Moore, 2006). In addition, Downes and Nunes (2013) argue that big-bang disruption, which is enabled by new digital platforms, such as those underlying the IOT, does not follow the five-step model. Rather, new products are perfected with a few trial users and then are embraced quickly by the vast majority of the market. Again, the innovation must be mature enough for customers to adopt it rapidly.

\section{Unstructured ecosystems}

Unstructured ecosystems lack defined underlying structures and governance, stakeholder roles, and value-creating logics. There may not be appropriate or required participants in an emerging ecosystem; for example, IOT operators or potential customers could be missing. Pursuing new business opportunities demands opening new relationships in new industries, or extending existing relationships, takes time and is a challenge for managers. The complexity of an ecosystem is associated with the number of participants (Möller et al., 2005), and an early ecosystem is an unstructured, chaotic, and open playground for participants. The IOT is still in its infancy, just like the Internet once was. The Internet has been a driver for an incredible richness of rival and complementary business ecosystems that all use the Internet in different ways, such as the ecosystem anchored around Amazon Web Services (AWS), or the ecosystem anchored around Google's AdSense platform, or the mashup ecosystem enabled by open APIs and open data, or the many business ecosystems anchored around community-developed platforms. There is a need for the emergence of keystones that would shape the IOT business ecosystems through business model innovation (cf. Carbone, 2009). However, presently, it is too early to tell which will be the significant yet evolving ecosystems in the IOT field and which participant(s) will become keystone players within them. Such stakeholders could be, for example, an object/device supplier, a supplier of software infrastructure, a supplier of hosted solutions or smart services, an IOT operator, a value-added service provider or a full service integrator, data collector/analyzer, or even an (open source) user community (cf. Carbone, 2009). Therefore, instead of focusing on the key stakeholder(s), it may be better to focus on the generation and capture of value in the ecosystems. The unstructured IOT ecosystems result in the need for IOT-specific business model frameworks that help construct and analyze the ecosystem and business model choices and articulate this integrated value for the stakeholders.

\section{Potential Solutions}

We propose that managers can overcome the previously discussed challenges and be able to design feasible business models for the IOT if they change their focus towards an ecosystem approach of doing business and if they use business model design tools that consider the ecosystem nature of the IOT rather than emphasize an individual company's self-centered objectives. These endeavours are discussed in this section.

We suggest that managers need to shift their focus from "the business model of a firm" to "ecosystem business models". However, the term "ecosystem business models" has at least three interpretations in the literature. First, the term can refer to a business model with specific properties - in this case, a business anchored in ecosystem concepts (e.g., the concept of a "green business model" that appeals to ecologically-motivated stakeholders and has specific "green" qualities) (Westerlund, 2013). Second, an ecosystem business model (or category of business models) can be shared by participants of an ecosystem (e.g., the term "fabless semiconductor business model", which implies that all fabless semiconductor firms are more or less the same) (Low \& Muegge, 2013). Third, it can refer to a construct at a level of analysis above the firm that explains how the entire ecosystem works towards common goals rather than how the firm-level business works (cf. Bat- 


\title{
Designing Business Models for the Internet of Things
}

\author{
Mika Westerlund, Seppo Leminen, and Mervi Rajahonka
}

tistella et al., 2013). However, the third interpretation usually refers to the ecosystem structure and mechanisms rather than focusing on the ecosystem as a business model (Ritala et al., 2013).

Rather than understanding these various interpretations as distinct concepts, this study understands them as different views of the same phenomena. We argue that an ecosystem business model is composed of a set of value pillars (cf. Osterwalder and Pigneur, 2010) anchored in ecosystems, which focus on both the firm's method of creating and capturing value as well as any part of the ecosystem's method of creating and capturing value to the ecosystem.

There have been attempts to define the IOT business ecosystem from the platform perspective (cf. Mazhelis et al., 2012), but the present focus of IOT players on fragmented solutions and applications fails to support these efforts. The basic approach towards understanding IOT business models is looking at the value for all actors in the IOT business ecosystem. This approach identifies the value for the actors that enable the IOT platform. Many telecommunications vendors and operators, as well as IOT platform vendors (e.g., machine-tomachine platform vendors), try to articulate the value of the IOT by using this approach to design their business models. However, the resulting business models are often biased toward the vendor and lack drivers for shared value as one of the explicit components.

This study underlines a need to understand integrated value drivers (i.e., shared overall value for an entire IOT ecosystem) rather than fragmented value drivers (i.e., individual actor's value from specific applications or services). Therefore, this study suggests shifting the focus on value creation and value capture in business models from the company level to the ecosystem level. Business model frameworks for the IOT should assume a higher-level perspective to articulate the integrated value of the IOT rather than address the fragmented value drivers. Weill and Vitale (2001) introduce a set of simple schematics intended to provide tools for the design of e-business initiatives. Their "e-business model schematics" include three classes of business model components: participants (firm of interest, customers, suppliers, and allies), relationships, and flows (money, information, product, or service flows).

Similarly, Tapscott, Lowy, and Ticoll (2000) suggest a value map for depicting how a business web operates. The value map depicts all key classes of participants (partners, customers, suppliers) and value exchanges between them (tangible and intangible benefits and knowledge). By the same token, Gordijn and Akkermans (2001) propose a conceptual modelling approach, the "e3-value ontology", to define how economic value is created and exchanged within a network of actors. Their ontology puts forward a number of useful valuerelated terms, such as value object and value port. Muegge (2011) argues that the engine driving innovation in an ecosystem is a resource cycle from the platform to the business ecosystem, to the developer community, and back to the platform. He also argues that the developer community is the locus of value creation (innovation) and the business ecosystem is the locus of value capture (innovation commercialization).

Lastly, Allee (2000) argues that a "value network" generates economic value through dynamic and complex exchanges between companies, suppliers, strategic partners, community, and customers and users. According to her, these value exchanges can be mapped as flow diagrams showing goods, services, and revenue streams, as well as knowledge flows, and creation of value. Dynamics, which is visible through the value network perspective, is relevant even when describing business models at a company level. For instance, Casadesus-Masanell and Ricart (2010) argue that a business model consists of a set of managerial choices and their consequences. Each choice may result in different outcome; thus, they drive dynamism. Moreover, they summarize three characteristics of a good business model: it is aligned with company goals, it is self-reinforcing (i.e., dynamic and cyclical), and it is robust. These characteristics support business sustainability in ecosystems (cf. Iansiti \& Levien, 2002).

\section{Principles of a Design Tool for Designing Ecosystem Business Models}

The major deficits in existing business model frameworks, such as the popular business model canvas (cf. Osterwalder \& Pigneur, 2010) or any other componentbased design tools include the fact that they focus on the architecture of the business model. They provide "an exploded view", showing the "parts of an engine". However, these frameworks fail to explain the dynamics between the components, or "how the engine works". Because a system cannot be understood by studying its parts detached from the entity, we aim to establish a foundation for a business model tool that considers the ecosystem nature of the IOT and focuses on the action instead of the parts. Previous research has suggested the integration of actors, various resource flows, and value exchange between them to map an 


\section{Designing Business Models for the Internet of Things}

\section{Mika Westerlund, Seppo Leminen, and Mervi Rajahonka}

ecosystem's operation (cf. Battistella et al., 2013; Ritala et al., 2013). Drawing from the ideas presented by, for example Allee (2000) on value networks, our principles for designing ecosystem business models build on different value flows and aspects in the IOT ecosystem.

The relevant literature shares the view that business models are about value creation and value capture. We argue that managers can design viable IOT business models by taking into consideration a variety of aspects related to these two essential value tasks. First, there are different value drivers in ecosystems. They comprise both individual and shared motivations of diverse participants, and promote the birth of an ecosystem to fulfill a need to generate value, realize innovation, and make money. We anticipate that a focus on shared value drivers is crucial to create a non-biased, win-win ecosystem. Without respect for the objectives of other actors, a long-term relationship cannot be built. However, each separate value driver will also serve as an individual value node's motivational factor. Sustainability, cybersecurity, and improved customer experience are examples of value drivers that different participants may share in an IOT ecosystem.

Second, these value nodes include various actors, activities, or (automated) processes that are linked with other nodes to create value. Moreover, these nodes may include autonomous actors, such as smart sensors, preprogrammed machines, and linked intellingence (avatars). Thus, the ecosystem is a compound of different value nodes; in addition to single activities, automated services, and processes, individuals, or commercial and nonprofit organizations, these value nodes may be groups of such organizations, networks of organizations, or even groups of networks. In short, there is a significant heterogeneity of value nodes in IOT ecosystems.

Third, value exchanges refer to an exchange of value by different means, resources, knowledge, and information. The value exchange occurs between and within different value nodes in the ecosystem, and exchanges can be described through different value flows. Literature on value networks (e.g., Allee, 2000) describes these flows as tangible and intangible. Fundamentally, these flows show "how the engine works" by exchanging resources, knowledge, money, and information by different means. In other words, they describe the action that takes place in the business ecosystem in order to create and capture value. Value exchanges are crucial, because they also specify how revenues are generated and distributed in the ecosystem.
Fourth, not all created value is meaningful from the commercialization point of view. Value extract refers to a part of ecosystem that extracts value; in other words, it shows the meaningful value that can be monetized and the relevant nodes and exchanges that are required for value creation and capture. Value extract is a useful concept because it can help to focus on a relevant portion of the ecosystem; for example, a manager can "zoom in" and "zoom out" of the ecosystem to focus on something that is beneficial from the business point of view. This portion may be single activities, automated processes, individuals, or commercial and nonprofit organizations, or groups of such organizations, networks of organizations, or even groups of networks and value flows between these nodes. Value extract is helpful in defining the core value and its underlying aspects in the ecosystem.

Finally, the concept of value design illustrates how value is deliberately created and captured in an ecosystem. That is, value design is an overall architecture that maps the foundational structure of the ecosystem business model. On one hand, it provides boundaries for the ecosystem and describes the whole entity that creates and captures value. On the other hand, it is a sum of the four value pillars and results in a pattern of operation. In this vein, value design is a concept that is quite similar to the concept of business model. The difference is that, whereas a "business model" is typically associated with the business model of a firm, value design can be defined to apply at the ecosystem level. Thus, we argue that "value design" could be better suited to the context of ecosystems than "business model". In addition, we view that different value designs can be categorized, examined, and compared similarly to different types of business model.

Figure 1 illustrates the key value pillars, which we anticipate to be better suited for designing business models for ecosystems than the components put forward by previous business model frameworks. We believe that these value pillars serve as a basis for a new type of design tool for ecosystem business models. The actual tool needs further research and could likely be built around the idea of value webs and their related illustrations.

There are certainly limitations in our research, but this conceptual study is intended to present the first attempt - "a plum pudding model" (tinyurl.com/36x8pv9) to create a business model design tool for the IOT ecosystem. Although we have not provided an actual tool or its illustration at the present, the study established 


\section{Designing Business Models for the Internet of Things}

\section{Mika Westerlund, Seppo Leminen, and Mervi Rajahonka}

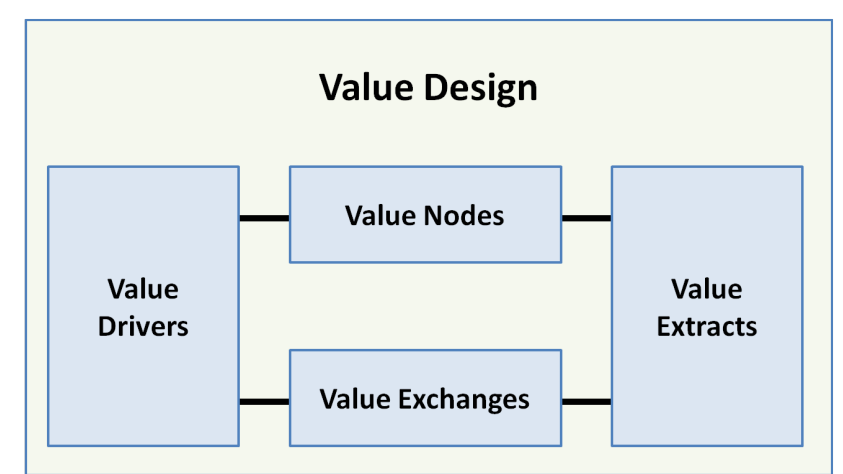

Figure 1. Key pillars of a business model design tool for IOT ecosystems

key pillars of the anticipated tool. Future research should verify these pillars and apply them into practice in order to develop the tool. Therefore, we call for more research on business model frameworks in the emerging IOT context, which is a fruitful field for developing a design tool for ecosystem business models. The IOT field has potential not only to radically change our lives, but also our ways of thinking about networked business.

\section{Conclusions}

This research focused on the challenges of designing business models for the emerging Internet of Things (IOT). The study acknowledged that there are ongoing paradigm shifts towards ecosystem thinking both in the discussion of platforms and in the design of business models. The study highlighted three major problems that prevent companies from designing business models and monetizing the IOT; the diversity of objects, the immaturity of innovation, and the unstructured ecosystems. We argue that managers can overcome these challenges and design successful business models if they focus on the ecosystem approach of doing business and use business model design tools that consider the ecosystem nature of the IOT.

We provided grounds for a novel tool for designing ecosystem business models required in the IOT context. The pillars of the tool build on the different aspects of creating and capturing value in the ecosystem. They consist of the drivers, nodes, exchanges, and extracts of value. The pillars are interconnected, and, in contrast to existing business model frameworks, they aim to explain the flows and action of a business model rather than components of the model. That way, they form the value design, which is a concept comparable to that of a business model. This aim underlines a shift in scholarly and managerial thinking from the business model of a firm towards ecosystem business models, in which every participant's business model depends on the others in the ecosystem.

Our study contributes to managerial understanding of ecosystem business models by different means. First, the study addresses the value pillars that managers should be looking at when designing business models in IOT ecosystems. By identifying value pillars, managers will be able to broaden their views on business model development and procedures from a single-company perspective to a broader, ecosystem context. For the ecosystem to bloom, the business models of different actors and the entire ecosystem should somehow resonate; the pieces of the puzzle should fit together. This on one hand guarantees that the ecosystem as a whole moves in the same direction, and on the other hand, guarantee that the business models of different actors are complementary. For example, if one actor wants to streamline its processes, another actor can receive new business by offering new solutions to meet the needs of the first actor. Second, managers may review their existing underlying assumptions on business model design by designing new value nodes and value exchanges in an ecosystem. This change of a mindset is important because it allows managers to view business model design - and later receive related benefits - at an ecosystem level instead of the restricted company level. We argue that our vision of a possible business model design tool can be used for IOT-related issues, but is applicable in other emerging ecosystem-seeking structures where technological solutions are not yet ready and where existing industry borders must be crossed, if necessary. Finally, our value pillars enable managers to focus on value opportunities in the emerging IOT ecosystem by understanding key challenges of ecosystem business model design.

For academics, this study is important because we call for a major shift in business model research. We argue that business models should not be broken down into a number of unconnected components in the way of the majority of previous business model research. Instead, studies should focus on investigating ecosystem business models and the way these models generate and capture value through different value flows. That way, the concept of business model, which is traditionally associated with a single organization's business model, could be replaced with the term "value design", which is better suited to ecosystems. 


\section{Designing Business Models for the Internet of Things}

\section{Mika Westerlund, Seppo Leminen, and Mervi Rajahonka}

\section{About the Authors}

Mika Westerlund, D.Sc. (Econ) is an Assistant Professor at Carleton University's Sprott School of Business in Ottawa, Canada. He previously held positions as a Postdoctoral Scholar in the Haas School of Business at the University of California Berkeley and in the School of Economics at Aalto University. Mika earned his doctoral degree in Marketing from the Helsinki School of Economics. His doctoral research focused on software firms' business models and his current research interests include open and user innovation, business strategy, and management models in high-tech and serviceintensive industries.

Seppo Leminen holds positions as Principal Lecturer at the Laurea University of Applied Sciences and Adjunct Professor in the School of Business at Aalto University in Finland. He holds a doctoral degree in Marketing from the Hanken School of Economics and a licentiate degree in Information Technology from the Helsinki University of Technology (now the School of Electrical Engineering at Aalto University). His doctoral research focused on perceived differences and gaps in buyer-seller relationships in the telecommunication industry. His research and consulting interests include living labs, open innovation, value co-creation and capture with users, neuromarketing, relationships, services, and business models in marketing as well as management models in high-tech and service-intensive industries.

Mervi Rajahonka, D. Sc. (Econ) is a Researcher at Aalto University's School of Business in Helsinki, Finland. She also holds a Master's degree in Technology from the Helsinki University of Technology and a Master's degree in Law from Helsinki University. Mervi earned her doctoral degree in Logistics from the Department of Information and Service Economy at the Aalto University. Her research interests include supply chain management, business models, modularity, processes, and service innovations. Her research has been published in a number of journals in the areas of logistics, services, and operations management.

\section{Acknowledgments}

We wish to thank Mr. Sohail Islam whose recent MEng project on IOT business models - which he recently completed within the Technology Innovation Management program at Carleton University in Ottawa, Canada - sparked fruitful ideas put forward in the early version of this study. In addition, we would like to thank the anonymous reviewer whose excellent comments helped us to develop the study.

\section{References}

Achtenhagen, L., Melin, L., \& Naldi, L. 2013. Dynamics of Business Models - Strategizing, Critical Capabilities and Activities for Sustained Value Creation. Long Range Planning, 46(6): 427-442. http://dx.doi.org/10.1016/j.lrp.2013.04.002

Barabasi, A.-L. 2002. Linked: The New Science of Network. Cambridge: Perseus Publishing.

Battistella, C., Colucci, K., De Toni, A.F., \& Nonino, F. 2013. Methodology of Business Ecosystems Network Analysis: A Case Study in Telecom Italia Future Centre. Technological Forecasting \& Social Change, 80: 1194-1210.

Allee, V. 2000. Reconfiguring the Value Network. Journal of Business Strategy, 21(4): 36-39. http://dx.doi.org/10.1108/eb040103

Carbone, P. 2009. The Emerging Promise of Business Ecosystems. Open Source Business Resource, February 2009: 11-16. http://timreview.ca/article/227

Casadesus-Masanell, R., \& Ricart, J.E. 2010. From Strategy to Business Models and onto Tactics. Long Range Planning, 43(2-3): 195-215. http://dx.doi.org/10.1016/j.lrp.2010.01.004

CERP-IoT. 2009. Internet of Things Strategic Research Roadmap. Cluster of European Projects. http://www.grifs-project.eu/data/File/CERP-IoT\%20SRA_IoT_v1l.pdf

Cusumano M.A., \& Gawer, A. 2002. The Elements of Platform Leadership. MIT Sloan Management Review, 43(3): 51-58.

Demil, B., \& Lecoq, X. 2010. Business Model: Toward a Dynamic Consistency View of Strategy. Long Range Planning, 43(2-3): 227-246. http://dx.doi.org/10.1016/j.lrp.2010.02.004

Downes, L., \& Nunes, P.F. 2013. Big-Bang Disruption. Harvard Business Review, 91(3): 44-56.

Espada, J.P., Martínez, O.S., García-Bustelo, B.C.P., \& Lovelle, J.M.C. 2011. Virtual Objects on the Internet of Things. International Journal of Artificial Intelligence and Interactive Multimedia, 1(4): 24-30. http://dx.doi.org/10.9781/ijimai.2011.144 


\section{Designing Business Models for the Internet of Things}

\section{Mika Westerlund, Seppo Leminen, and Mervi Rajahonka}

Evans, D. 2011. The Internet of Things - How the Next Evolution of the Internet Is Changing Everything. Cisco Internet Business Solutions Group (IBSG) White Paper.

Gershenfeld, N., \& Vasseur, J.P. 2014. As Objects Go Online: The Promise (And Pitfalls) of the Internet of Things. Foreign Affairs, 93(2): 60-67.

Gomez, J., Huete, J.F., Hoyos, O., Perez, L., \& Grigori, D. 2013. Interaction System Based on Internet of Things as Support for Education. Procedia Computer Science, 21: 132-139.

http://dx.doi.org/10.1016/j.procs.2013.09.019

Gordijn, J., \& Akkermans, H. 2001. Design and Evaluation of e-Business Models. IEEE Intelligent Systems, 16(4): 11-17. http://dx.doi.org/10.1109/5254.941353

Iansiti, M., \& Levien, R. 2002. Keynotes and Dominators: Framing Operating and Technology Strategy in a Business Ecosystem. Harvard Business School Working Paper, No. 03-061. Cambridge, MA: Harvard Business School.

ITU. 2005. The Internet of Things. ITU Internet Reports 2005. http://www.itu.int/osg/spu/publications/internetofthings/

Kyriazis, D., \& Varvarigou, T. 2013. Smart, Autonomous and Reliable Internet of Things. Procedia Computer Science, 21: 442-448. http://dx.doi.org/10.1016/j.procs.2013.09.059

Leminen, S., Westerlund, M., Rajahonka, M., \& Siuruainen, R. 2012. Towards IOT Ecosystems and Business Models. In S. Andreev, S. Balandin, \& Y. Koucheryavy (Eds.). Internet of Things, Smart Spaces, and Next Generation Networking - Lecture Notes in Computer Science, Volume 7469: 15-26. Berlin: Springer.

Low A., \& Muegge, S. 2013. Keystone Business Models for Network Security Processors. Technology Innovation Management Review, 3(7): 25-33.

http://timreview.ca/article/703

Mazhelis, O., Luoma, E., \& Warma, H. 2012. Defining an Internet-ofThings Ecosystem. In S. Andreev, S. Balandin, \& Y. Koucheryavy (Eds.). Internet of Things, Smart Spaces, and Next Generation Networking - Lecture Notes in Computer Science, Volume 7469: 1-14. Berlin: Springer.

Moore, J.F. 1996. The Death of Competition: Leadership \& Strategy in the Age of Business Ecosystems. New York: Harper Business.

Moore, G.R. 2006. Crossing the Chasm - Marketing and Selling Technology Products to Mainstream Customers. (2nd Ed). Padstow: Cornwall: Capstone Publishing Ltd.

Morris, M., Schindehutte, M., \& Allen, J. 2005. The Entrepreneur's Business Model: Toward a Unified Perspective. Journal of Business Research, 58: 726-35.

http://dx.doi.org/10.1016/j.jbusres.2003.11.001

Muegge S. 2011. Business Ecosystems as Institutions of Participation: A Systems Perspective on Community-Developed Platforms. Technology Innovation Management Review, 1(2): 4-13. http://timreview.ca/article/495.

Muegge, S. 2012. Business Model Discovery by Technology Entrepreneurs. Technology Innovation Management Review, 2(4): 5-16. http://timreview.ca/article/545.

Muegge, S. 2013. Platforms, Communities, and Business Ecosystems: Lessons Learned About Technology Entrepreneurship in an Interconnected World. Technology Innovation Management Review, 3(2): 5-15. http://timreview.ca/article/655
Möller, K., Rajala, A., \& Svahn, S. 2005. Strategic Business Nets - Their Type and Management. Journal of Business Research, 58(9): 12741284. http://dx.doi.org/10.1016/j.jbusres.2003.05.002

Oriwoh, E., Sant, P., \& Epiphaniou, G. 2013. Guidelines for Internet of Things Deployment Approaches - The Thing Commandments. Procedia Computer Science, 21: 122-131.

http://dx.doi.org/10.1016/j.procs.2013.09.018

Osterwalder, A., Pigneur, Y., \& Tucci, C. L. 2005. Clarifying Business Models: Origins, Present and Future of the Concept. Communications of the Association for Information Science, 16(1): 1-25. http://aisel.aisnet.org/cais/vol16/iss1/1

Osterwalder, A., \& Pigneur, Y. 2010. Business Model Generation: A Handbook for Visionaries, Game Changers, and Challengers. Zurich, Switzerland: Business Model Foundry.

Peltoniemi, M. 2005. Business Ecosystem: A Conceptual Model of an Organization Population from the Perspectives of Complexity and Evolution. Research Reports 18. Tampere, Finland: E-Business Research Center.

Rajala, R., \& Westerlund, M. 2008. Capability Perspective of Business Model Innovation: An Analysis in the Software Industry. International Journal of Business Innovation and Research, 2(1): 71- 89. http://dx.doi.org/10.1504/IJBIR.2008.015936

Ritala, P., Agouridas, V., Assimakopoulos, D., \& Gies, O. 2013. Value Creation and Capture Mechanisms in Innovation Ecosystems: A Comparative Case Study. International Journal of Technology Management, 63(3/4): 244-267. http://dx.doi.org/10.1504/IJTM.2013.056900

Schweizer, L. 2005. Concept and Evolution of Business Models. Journal of General Management, 31(2): 37-56.

Shafer, S. M., Smith, H. J., \& Linder, J. C. 2005. The Power of Business Models. Business Horizons, 48(3): 199-207. http://dx.doi.org/10.1016/j.bushor.2004.10.014

Tapscott, D., Lowy, A., \& Ticoll, D. 2000. Digital Capital: Harnessing the Power of Business Webs. Cambridge, MA: Harvard Business School Press.

Teece, D.J. 2010. Business Models, Business Strategy and Innovation. Long Range Planning, 43(2-3): 172-194. http://dx.doi.org/10.1016/j.lrp.2009.07.003

Timmers, P. 1998. Business Models for Electronic Markets. Electronic Markets, 8(2): 3-8. http://dx.doi.org/10.1080/10196789800000016

Uckelmann, D., Harrison, M., \& Michahelles, F. 2011. An Architectural Approach Towards the Future Internet of Things. In D. Uckelmann, M. Harrison, \& F. Michahelles (Eds.), Architecting the Internet of Things: 1-24. Berlin: Springer.

Weill, P., \&Vitale, M. R. 2001. Place to Space: Migrating to e-Business Models. Cambridge, MA: Harvard Business School Press.

Weiller, C., \& Neely, A. 2013. Business Model Design in an Ecosystem Context. University of Cambridge Working Papers. Cambridge, UK: Cambridge Service Alliance.

Westerlund, M. 2013. TIM Lecture Series - Green Business Models To Change The World: How Can Entrepreneurs Ride the Sustainability Wave? Technology Innovation Management Review, 3(7): 53-57. http://timreview.ca/article/70 


\section{Designing Business Models for the Internet of Things}

Mika Westerlund, Seppo Leminen, and Mervi Rajahonka

Wurster, L.F. 2014. Emerging Technology Analysis: Software Licensing and Entitlement Management Is the Key to Monetizing the Internet of Things. Gartner Research Report G00251790. Stamford, USA: Gartner, Inc.

Zott, C., \& Amit, R. 2008. The Fit Between Product Market Strategy and Business Model: Implications for Firm Performance. Strategic Management Journal, 29(1): 1-26.

http://dx.doi.org/10.1002/smj.642
Zott, C., Amit, R., \& Massa, L. 2011. The Business Model: Recent Developments and Future Research. Journal of Management, 37(4): 10191042.

http://dx.doi.org/10.1177/0149206311406265

Citation: Westerlund, M., Leminen, S., \& Rajahonka, M. 2014. Designing Business Models for the Internet of Things. Technology Innovation

Management Review, 4(7): 5-14. http://timreview.ca/article/807

Keywords: business model, Internet of Things, IOT, ecosystem, design tool, value, value design 